\title{
STUDY ON THE CHARACTERISTICS OF HMONG MINORITY 'S VERNACULAR DWELLINGS AT HUAYUAN COUNTY IN XIANGXI AREA (CHINA)
}

\author{
L. Long ${ }^{1}$, Z. Gan ${ }^{1}$, D. Zhang ${ }^{1, *}$, G. Semprebon ${ }^{2}$ \\ ${ }^{1}$ Beijing University of Civil Engineering and Architecture, $\mathrm{N}^{\circ} 1$ Zhanlanguan Road, Xicheng District, Beijing, China - (longlin, \\ strider)@tntlab.cn, zhangdy@bucea.edu.cn \\ ${ }^{2}$ Politecnico di Milano, Shanghai Jiao Tong University and Beijing University of Civil Engineering and Architecture - \\ gerardo.semprebon@polimi.it
}

Commission II - WG II/8

KEY WORDS: Huayuan County, Hmong minority, Vernacular Dwellings, Space Layout, Design with Nature

\begin{abstract}
:
Hmong vernacular dwellings are an indispensable and essential branch of traditional Chinese architecture, which bears the profound history of the integration of minority culture and Han culture for thousands of years. As a typical representative of the Hmong settlement in China, the Hmong Village in Huayuan County, western Hunan Province, has the distinct characteristics of respecting nature and making good use of terrain in the construction of vernacular dwellings, which embodies the unique regional, historical, cultural and national character. Firstly, the article analyzes the influence of terrain, landform, climatic environment, historical culture, and social structure on the layout, shape, and materials of the rural homes of the Hmong people in Huayuan County. Secondly, by analyzing the elements of the courtyard space, the layout characteristics of the courtyard, and the organization mode of the courtyard group, the overall spatial characteristics of the residential courtyard are analyzed. At the same time, from the perspective of a single residential house, to sort out the characteristics of its type as well as the floor plan, building structure, material colour, and detailed decoration. Finally, it emphasizes that the Hmong vernacular dwellings in Huayuan County, embody the distinctive cultural connotation of the Hmong nationality, and show the unique aesthetic and romantic sentiment of the Hmong vernacular architecture to the world.
\end{abstract}

\section{INTRODUCTION}

Vernacular dwellings are folk buildings that are formed and developed according to local conditions under the influence of historical culture, regional characteristics, traditional customs, and national character. As an indispensable and essential branch of traditional Chinese architecture, Hmong vernacular dwellings bear the profound history of the integration of minority culture and Han culture for thousands of years. This material form culture is rooted in the mysterious and natural primitive Wuchu Culture. It reflects the wisdom of the Hmong people in building a house in compliance with nature and skillful choices, and it also shows the lively scenes of the Hmong people in western Hunan.

Huayuan County has been the core area where Hmong people live together in Hunan, Guizhou, and Sichuan (Chongqing) border areas since ancient times (Figure 1). It belongs to the eastern edge of the Yunnan-Guizhou Plateau and the middle part of the Wuling Mountains. It is one of the largest Hmong people's settlement counties in western Hunan. This article takes several well-preserved, and geographical features of Hmong vernacular dwellings in Huayuan County as a research sample interprets the spatial characteristics of Hmong 's traditional houses in the area and explores the connotation of Hmong culture through its physical space representation.

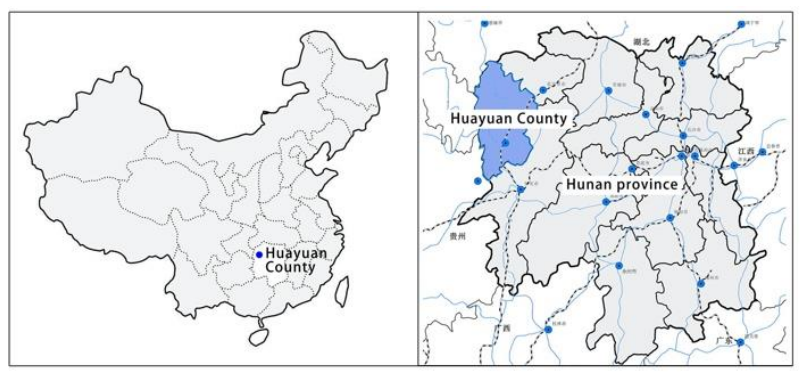

Figure 1. Location Map of Huayuan County.

\section{INFLUENTIAL FACTORS OF THE CHARACTERISTICS OF THE VERNACULAR DWELLINGS IN HMONG NATIONALITY IN HUAYUAN COUNTY}

\subsection{Natural Environment}

2.1.1 Terrain and Landform Features: Huayuan County is high in the south, gentle in the middle, and wide in the north. The landforms are rich in types, including plains, hills, hillocks, mountain plains, and mountainous areas. Huayuan County has many mountains and little fields. A saying of nine mountains, half water, and half fields.

\footnotetext{
* Corresponding author
} 
The Hmong folk proverb also says: Hakkas live on a street, Zhong lives by a river, and Hmong lives in a hill. Therefore, the Hmong people attach great importance to the land, leaving the more fertile and flat land for farming, which makes the overall residences show the layout characteristics of mountains (Figure 2).

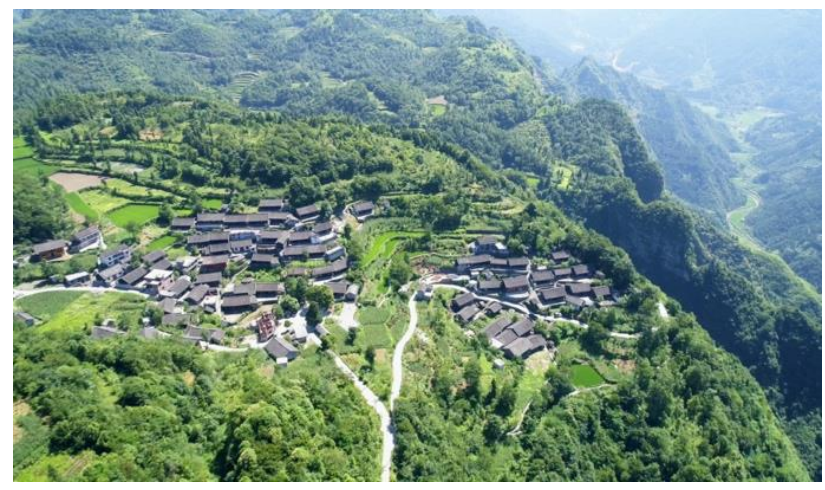

Figure 2. Aerial View of Jinlong Village.

2.1.2 Climatic characteristics: Huayuan County belongs to the subtropical monsoon mountain humid climate zone and has distinct continental climate characteristics. The three-level stepped mountainous landform makes three distinct climate zones with different heat and precipitation. Generally, the temperature gradually decreases from north to south, and precipitation gradually increases. Due to the complicated geographical topography and the distinct microclimates in various regions of the country, temperature differences in different regions will affect the building shape and the use of materials. Among them, the central and northern regions of Huayuan County have concentrated rainfall. During the season of rain and heat, the building materials, doors and windows are mainly set up for ventilation and heat dissipation, while the climate in the southern Alpine platform area is cold, with high humidity and the use of building materials is mainly cold and moisture-proof.

\subsection{Human environment}

2.2.1 Historical changes: The Chinese Hmong appeared almost at the same time as the Han but suffered successive failures during the war and were forced to carry out longdistance and long-term migration. The wars and tortuous migration have led to the Hmong people having to choose a remote mountain area as a place of living. The harsh and closed living environment has delayed the development of the Hmong society. As a result, the ancient Hmong people were less affected by the feudal dynasty in terms of ideology and culture, and the ventilation dwellings largely retained their cultural characteristics in the area.

2.2.2 The WuChu Culture: During the Spring and Autumn Period, some ancestors of the Hmong nationality chose to settle in the Jingchu area. They continued to expand their territory and established the name "Chu." As the primary resident of the Chu country, the Hmong nationality in Western Hunan has retained an influential witch culture and passed on with other minority residents communicating with each other and producing Chu culture that merged Chinese culture with witch culture.
Although the Han culture has always influenced the Chu culture with the unification of the feudal dynasty, the fantasy and mysterious blood in the body have kept the mysterious elements of the Wuchu culture in the physical space form. Xiangxi Hmong vernacular dwellings expression has more original elements, natural atmospheres, and romantic colours than the Central Plains dwellings.

2.2.3 Customs and beliefs: The mountains of western Hunan are full of magical and unknowable things. Under the influence of the primitive belief that all things have spirits, the Hmong people believe that all things and phenomena have souls and worshiping nature and fearing ghosts and gods has become their religion. Therefore, the layout of the dwelling houses depends on the situation, adapts to local conditions, pursues harmony with the environment, and shows secure attachment and awe to nature.

At the same time, the sacrifice activities of the Hmong nationality are prevalent, among which the ancestor worship activities in the interior have a profound impact on the layout of residential buildings. In the past, the Hmong people in western Hunan used to place the ancestor worship sacrifice under the middle pillar of the fire pond room. Later, influenced by the Han culture, some Hmong people moved the sacrifice to the hall. The changes in sacrifice styles have changed the layout and structure of residential houses.

2.2.4 Social structure: Western Hunan Hmong families generally practice a patriarchal small family system. Family members are living together for two generations, and fewer than three generations live together. Most of the children are separated from their parents when they are married, and the family usually does not exceed four people. Therefore, the requirements for living space are simple, and only daily living needs to be met.

\section{THE OVERALL SPATIAL CHARACTERISTICS OF THE COURTYARD}

The mountains in the Huayuan area are undulating, the river is vertical and horizontal, and the terrain is three-dimensional. The following nature and being flexible are the characteristics of the layout of the homes of the Hmong people. In order to save the land, the courtyard adapts to the change of terrain. The layout of the courtyard does not pursue the integrity of the square; the orientation of the building does not demand to sit north to south. There is no clear axis and symmetry, and the spatial form reflects a free and easy, extensive, and romantic mood.

\subsection{Elements of Courtyard Space}

The residential courtyards of the Hmong nationality in the Huayuan area are different from the high walls and courtyards of the Han nationality. They are less constrained by the "ritual system." The main components include the main building, the compartment building, the subsidiary building, and the platform, some of which have low courtyard walls and courtyard door.

The main building: the main building is the most crucial element of the Hmong courtyard. It is built with its back to the mountain and facing the sun and tries to get sunshine. The building is usually used for sacrificing ancestors and daily life. It is three Bay, one floor in appearance, the two floors in the interior, and second floor is an attic for storage (Figure 3 ). 
The compartment building: it is a building set at right angles to the main room. Its appearance is similar to that of the main building. Its ridge is lower than that of the main one. It is usually two Bay, which is used as a guest room or dining room. If the room is a suspended building, the first floor is externally enclosed by brick or stone to form a closed space for the storage room. The second-floor air-drying is suitable for storing grain and storage. Sometimes it is also used as a dormitory for unmarried family members. There is a wooden railing around the building for drying the grain.
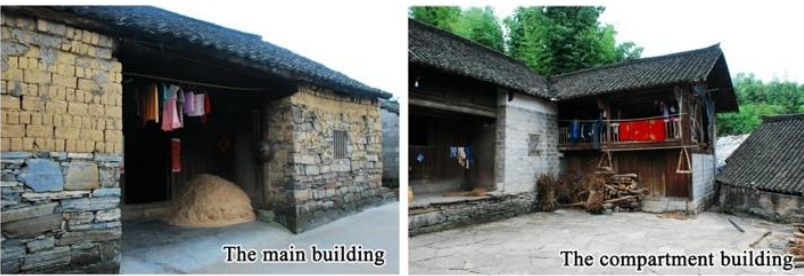

Figure 3. The main building and the compartment building.

The subsidiary building: it refers to an auxiliary structure on the side of the main, which is juxtaposed with the main house, or the "corner house" is added at the intersection of main building and compartment building. It has a simple structure and is mainly used as a toilet or captive livestock (Figure 4).

The platform: the courtyard in front of the main building is an unclosed platform space, also known as Shaiguping, it is a functional place for drying clothes and food, an open space for outdoor family activities, and a buffer zone for residential and external, private and public buffer zones.
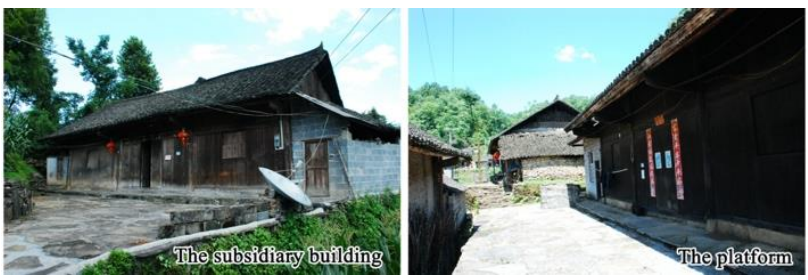

Figure 4 . The subsidiary building and the courtyard.

The low courtyard walls: the boundary of the courtyard plays a role in defining the courtyard. In order to ensure ventilation, most Hmong vernacular dwellings do not have a wall. Even if there is a wall, it is relatively low, usually between $0.6-1.5 \mathrm{~m}$, and repaired with stone or adobe bricks (Figure 5).

The courtyard door: a small gatehouse will be set up in front of the walled yard, called the "Chaomen". Affected by feng shui, the facing door usually opens at the southeast corner and faces differently from the main building in the courtyard.
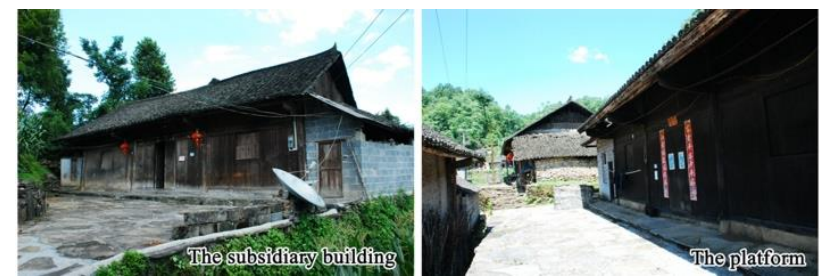

Figure 5. The low courtyard walls and the courtyard door.

\subsection{Courtyard Layout Characteristics}

Its courtyard organization mode of the vernacular dwellings of the Hmong people in Huayuan County is mainly "I" courtyard and "L" courtyard, and a small part is "U" courtyard (Figure $6)$.

An "I" courtyard is a courtyard with only one main building, some of which have subsidiary buildings on both sides, side by side with the main house.

The courtyard of the "L" type has a right angle between the main house and the compartment. The functions of the main house and the compartment complement each other, and the internal space is interconnected.

The "U" type courtyard is a kind of courtyard dam space which is formed based on the "L" type courtyard by adding compartments at the other end and is relatively closed with the main roof.
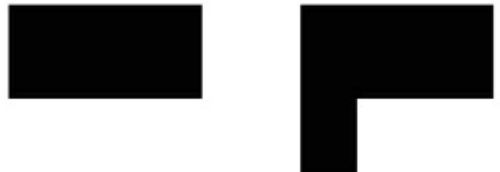

拐角院

"I" courtyard

\section{"L" courtyard}

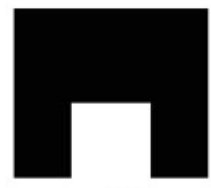

凹型院
Figure 6. The Courtyard Organization Mode of The Vernacular Dwellings.

\subsection{Courtyard Group Organization}

The organization patterns of the spatial patterns of the courtyard groups in the traditional villages of the Hmong people in Huayuan County are as follows:

3.3.1 Parallel splicing: Due to the limitation of the multiple dwellings, the courtyard groups are arranged parallel to the contour line according to the mountains. The courtyards and the courtyards are connected in parallel and are arranged in a line, forming a continuous building group (Figure 7). The total length and number vary, generally not more than 15 courtyards as a group.

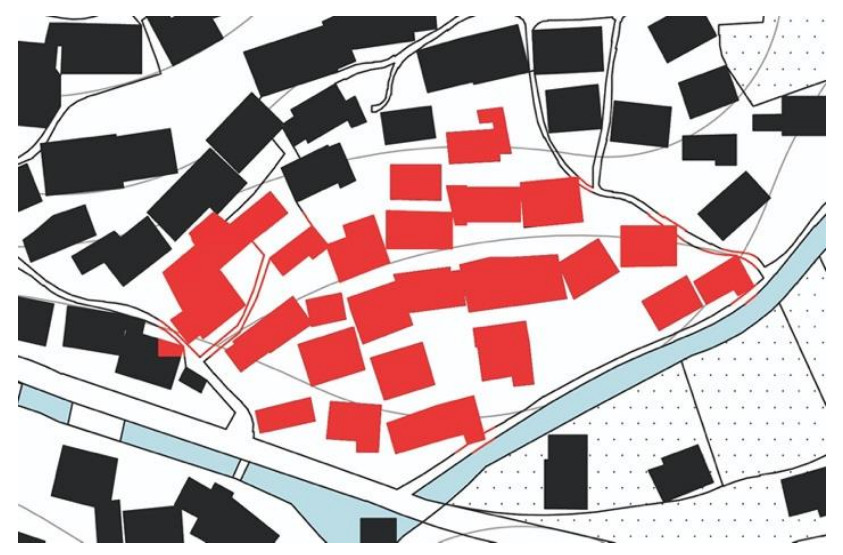

Figure 7. Parallel Splicing. 
3.3.2 Tandem splicing: The tandem arrangement of the courtyards perpendicular to the contour lines. Due to the steep mountains, the height differences between the courtyards are very different. Usually, the building roof of the previous courtyard is the same height as the platform of the latter courtyard. It is connected to streets and lanes of the contour line, and then the courtyards are connected by branches or steps in the form of steps or ramps (Figure 8). Generally, no more than 10 courtyards are grouped.

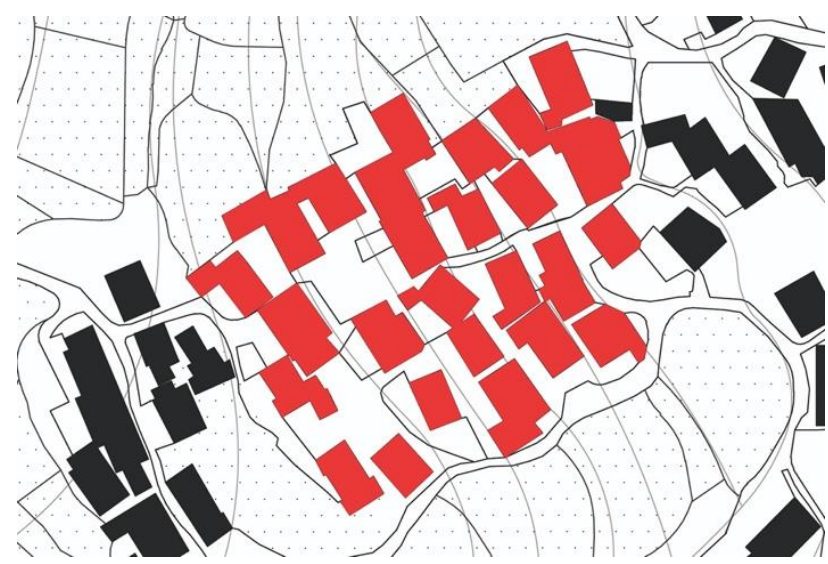

Figure 8. Tandem Splicing.

3.3.3 Group stitching: It is formed by the combination of parallel splicing and tandem splicing. Its scale is generally smaller than the parallel stitching mode and more massive than the series stitching mode. It usually consists of courtyards that are perpendicular to the contour line in series and courtyards that are horizontally parallel (Figure 9).

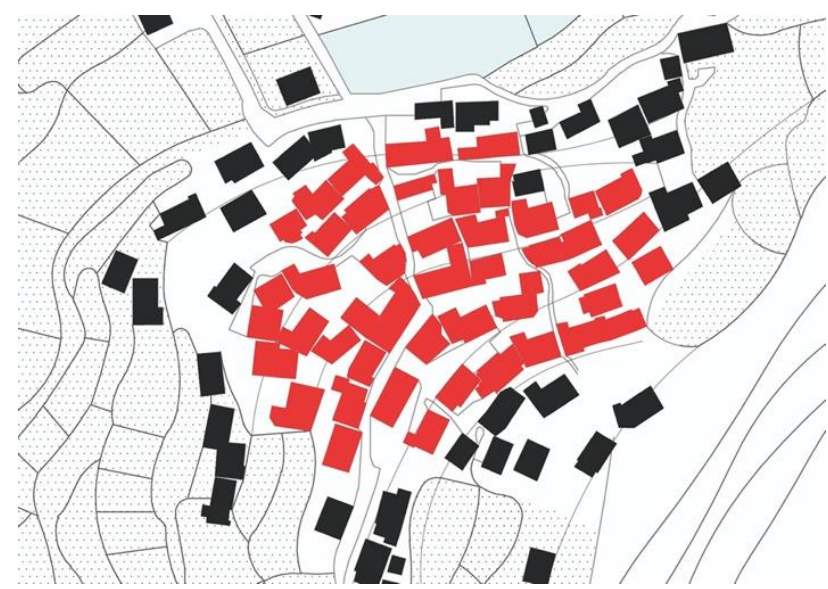

Figure 9. Group Stitching.

\section{SPATIAL CHARACTERISTICS OF SINGLE BUILDINGS}

\subsection{Buildings Type}

There are three types of Hmong vernacular dwellings in the Huayuan area, which are swallowed mouth houses, I-shaped houses, and cantilever-style hanging feet houses.

The main buildings are in the form of a concave house and a flat house. The first two types are mainly in the form of the main room, and the gallery-style stilts are used for the compartment building. The swallow mouth house has a concave entrance in the middle of the building (Figures 10 and 11), distributed in the southern region of Huayuan County with a relatively humid and cold climate."Swallowing" has many functions. On the one hand, it is a consideration of practical use. The relatively deep under eaves is conducive to wind protection and indoor lighting. It can also be used for daily rest and indoor and outdoor transitions. On the other hand, it also has Feng Shui's meaning of "Ju Bao Jin Cai."

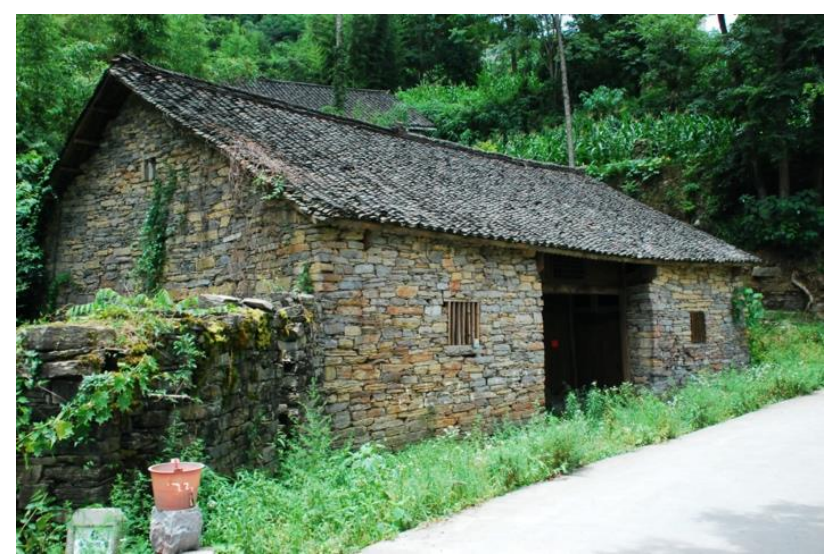

Figure 10. The Swallow Mouth Houses.

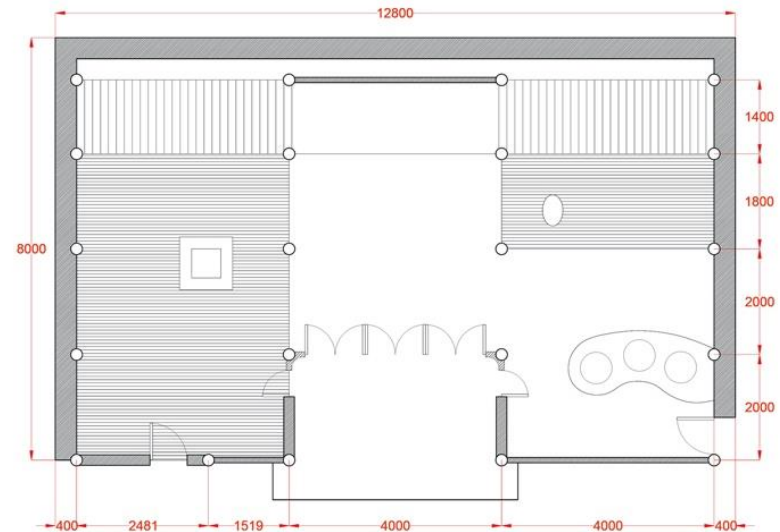

Figure 11. The Layout of Swallow Mouth Houses.

I-shaped houses adopt a "fully flat" floor layout that does not have a concave in the middle of the house, which is mainly distributed in the north-central region with a warmer climate (Figures 12 and 13). The smooth façade of this type of dwellings helps to ventilate the interior and increases the usable area inside the dwellings, making the building more spacious. The layout is the same as that of the swallow mouth houses, except that the attic space on the second floor is flexible, and sometimes the way of partial emptying is adopted.

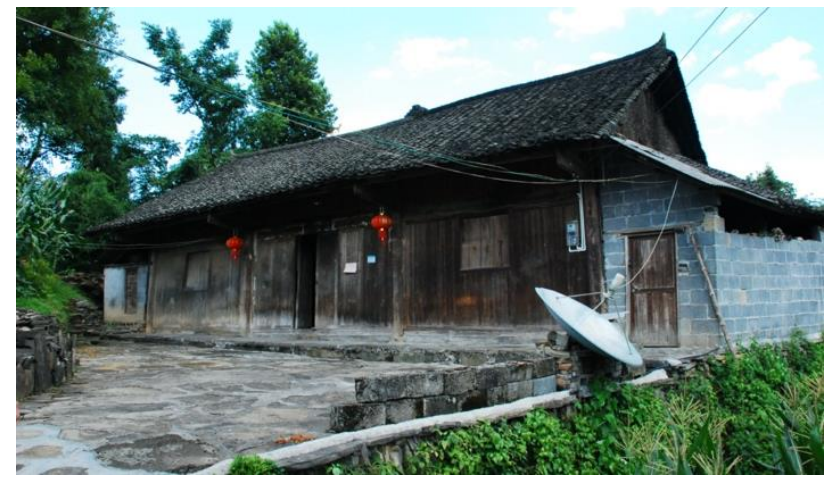

Figure 12. The I-shaped houses. 


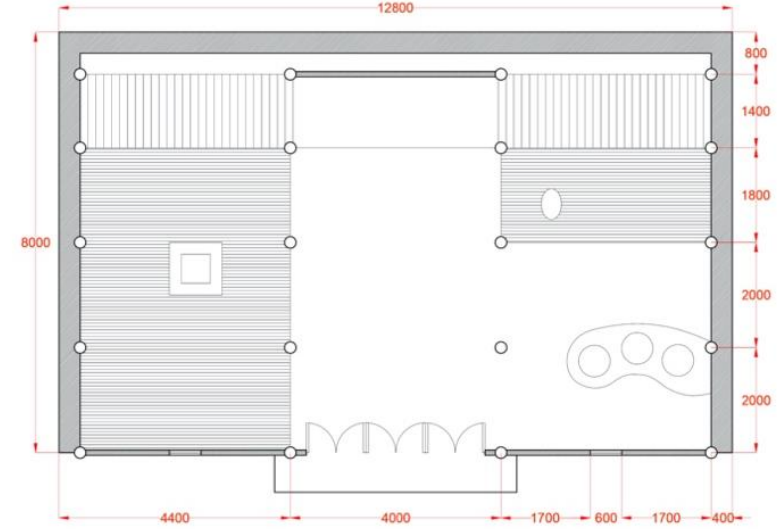

Figure 13. The Layout of I-shaped houses.

The Cantilever-style hanging foot building is named for its twostory floor structure, which is usually a two-story, two-bay apartment. Because the folks in the Xiangxi area have the buildings that do not deceive the host, the height and size of the room will not exceed the main building. However, its structure and decoration are more refined and dexterous than the main one, which makes the combination between the two shows both a pure atmosphere and a sense of ethereal clarity.

\subsection{Functional Layout}

Although the courtyard layout is free, the single building layout is orderly. The middle room is a hall house, which is a place for daily living, work, visitors, and sacrifices. In most cases, the hall house is not over-furnished, because many of the Hmong people's sacrificial activities are carried out indoors, and the hall room needs enough space for its use. The bays on both sides of the hall are side rooms, which are separated into front and back parts by thick cloth and black curtains. The front part of the right Bay is the kitchen, the front part of the left Bay is the fire pond, and the back part of the two side rooms is the bedroom. Apart from the need for ventilation and exhaust directly above the fire pond, the other two floors are usually used as storage space or as bedrooms for young people or guests (Figure 14).

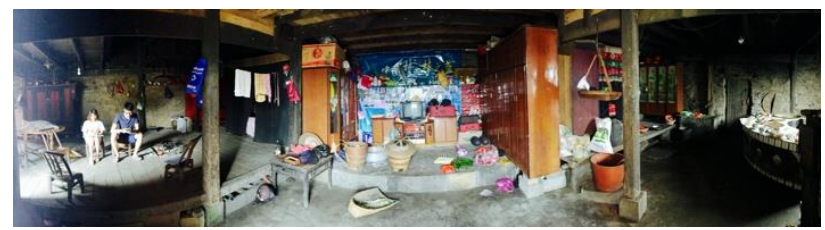

Figure 14. Internal Functional Layout.

As mentioned above, indoor ancestral worship activities have a profound impact on the layout and structure of residential buildings. In the past, the ancestral worship of the Hmong family was performed in the fire pond room. During the sacrifice, people stood in the hall house and worshiped in front of the ancestral tablets. Therefore, a relatively large and complete horizontal formation was required between the room and the fire pond space, and there is no centre pillar. When the sacrifice event is held in the hall house, the horizontal indoor space function changes, and the problem of the indoor centre pillar does not need to be considered. For the sake of structural stability, the residents would choose to live in the temple house with columns builded on both sides (Figure 15).

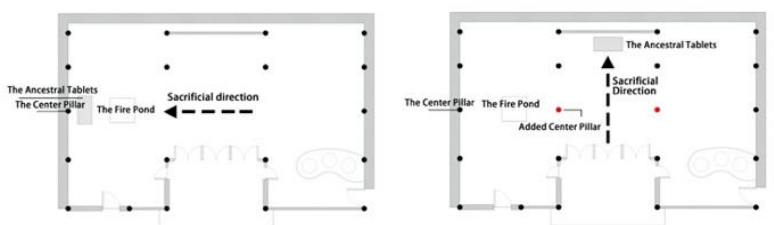

Figure 15. Impact of Changes in Sacrificial Direction on Building Structure.

\subsection{Building Structure}

The vernacular dwellings in Huayuan are built on the hills, and the buildings are made of local materials.

The main structure of the dwelling is columns and tie construction, which saves materials and make the shape lightweight and elegant. (Figure 16). It has the characteristics of Chinese traditional wooden structure building, that is, the wall falls, and the house does not fall.

The most common existing form of structure is five columns, eight short columns, and three rooms; there are also variants of " five columns, six short columns " and "three columns, six short columns. " There is no strict restriction on the number of columns and short columns, and no uniform regulation on space and height dimensions of houses (Figure 17). They can be adjusted according to the land-use situation and the requirements of householders. Generally, they pursue auspicious dimensions. Also, in order to block underground moisture, residential dwellings will raise the indoor floor and make the bottom overhead about $30 \mathrm{~cm}$ above the ground.

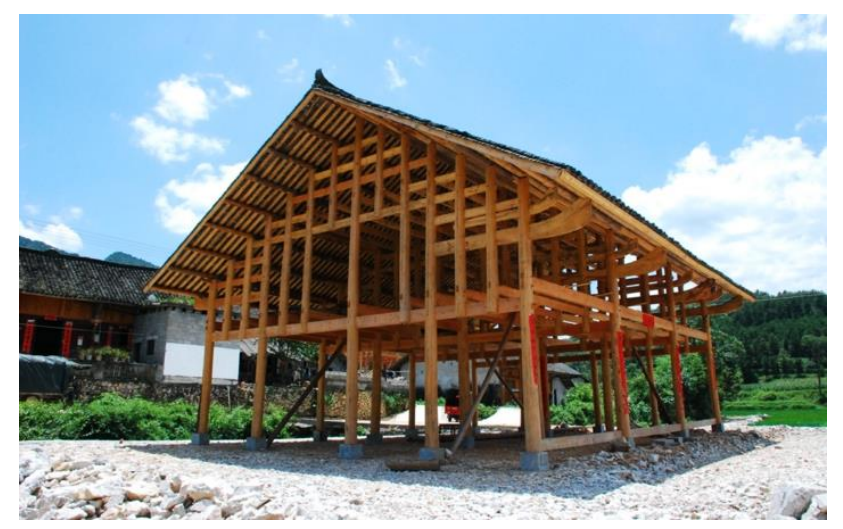

Figure 16. Building Structure.

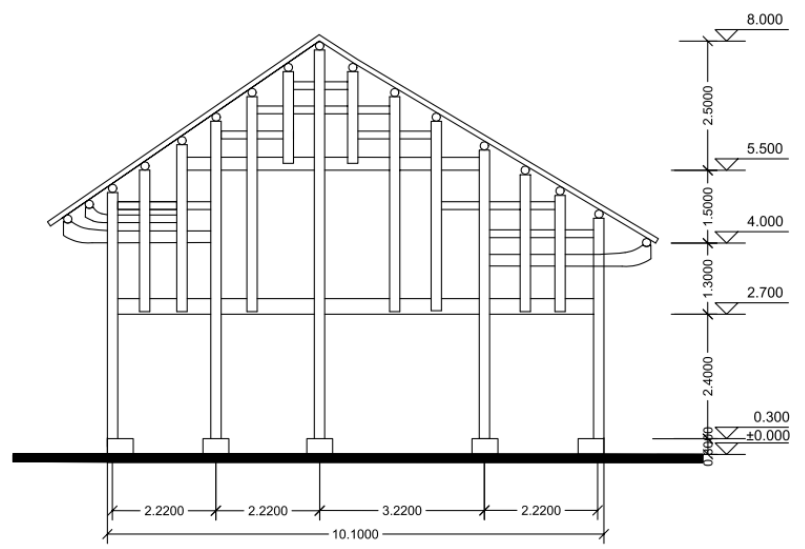

Figure 17. Section of Vernacular dwellings. 
The dwellings use overhanging eaves, often over 1.5 meters indepth, so many dwellings will also add columns to make eaves. The length of the teal directly affects the width of the corridor under the eaves. The style of the teal in the vernacular dwellings of Hmong Village is divided into single and double teasing. Single teasing refers to a piece of architrave that directly crosses the centre of the eaves column to be overhauled. Double teasing refers to two architraves that are overhauled. For the two piercings, the one is farther away, and the second one is smaller.

Also, due to the humid climate, the roof uses a "cold stall" method (Figure 18), instead of the gauntlet and rafters, the Yangtze tile is laid directly between the two rafters. This approach is to make the indoor humidity dissipate from the roof as soon as possible.

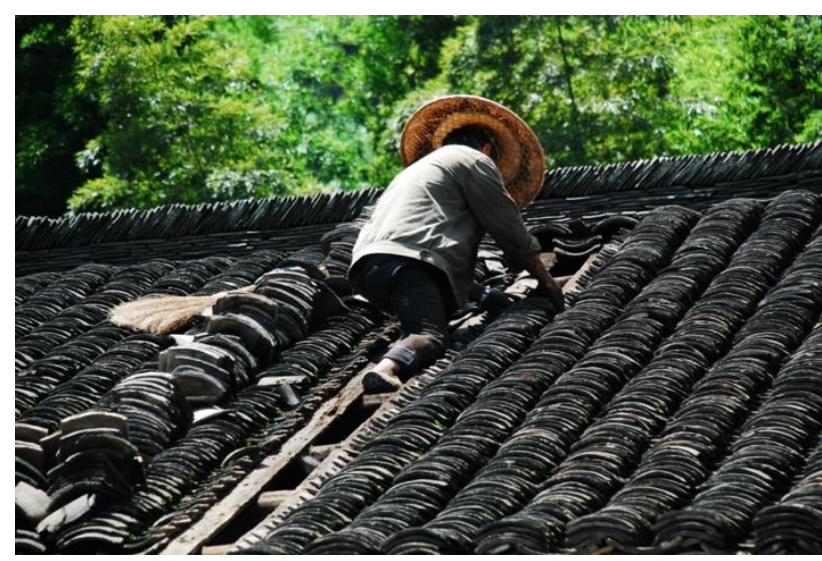

Figure 18. Cold Stall.

\subsection{Building Materials and Colours}

Western Hunan is rich in timber, and the residential structure is all made of wood. The dwelling materials are also taken from local sources, including stone, shale, fir board, adobe brick, and rattan wall (Figure 19). In order to cope with the humid climate, houses usually use moisture-proof materials such as stones, and the walls are different according to the difference in altitude and temperature. In the colder southern areas, stone and adobe bricks are often used to protect against humidity and cold. In the relatively warm central and northern regions, the rattan wall, thin wood, and other materials are used to promote heat dissipation. Among them, the rattan wall woven with local bamboo and rattan into a board surface and then covered with cow dung and soil has excellent ventilation.
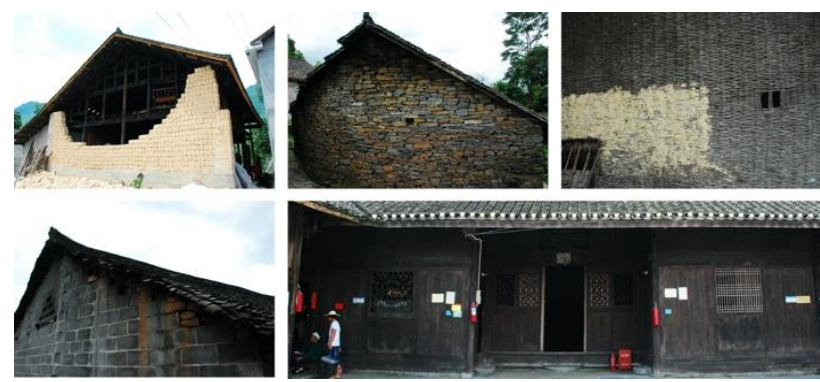

Figure 19. Building Materials.

The Hmong residences from local sources laid the overall colour of the village. The overall colour is mainly composed of the yellowish-brown colour of stone and soil and the dark grey colour of black tiles, which complements the surrounding landscape environment and exudes the charm of simplicity and agility.

\subsection{Building Decoration}

The decoration of the Hmong building is mainly in the easy-toshape wooden parts such as doors and windows, hanging gourds, as well as places that can reflect the characteristics of residential houses such as roof ridges and upslopes, which are light and straightforward.

The window and door are generous and straightforward. Geometric patterns separate the windows. The $2-3 \mathrm{~cm}$ wide strips of wood are riveted in different ways to form a square, diamond, or polygon shapes, which are combined repeatedly according to specific rules and rhythms. In addition to geometric patterns, doors, and windows also use plant and flower images to express their worship of nature (Figure 20).
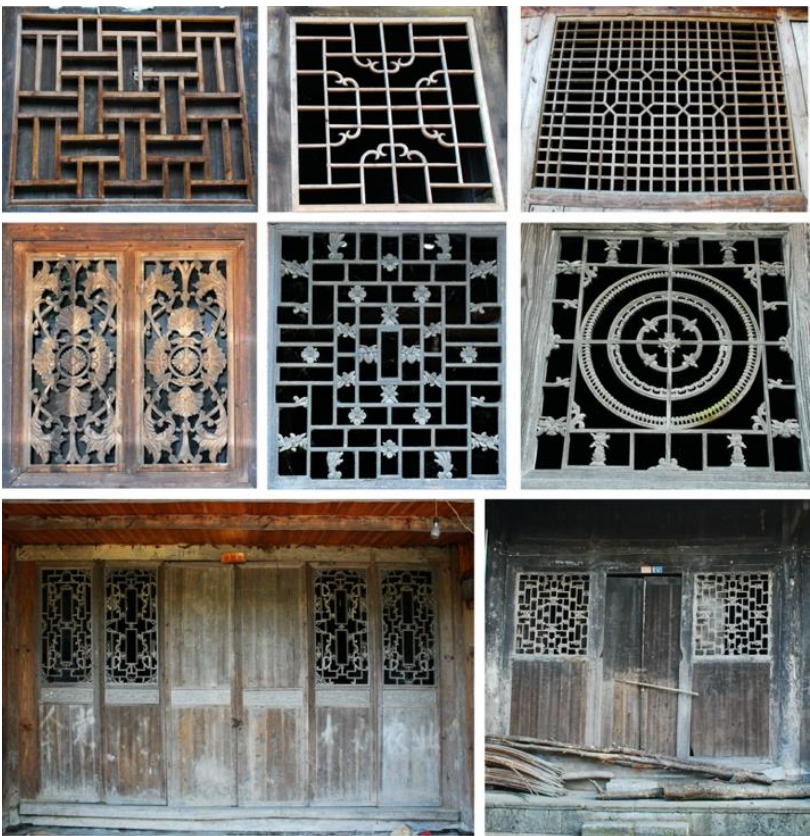

Figure 20. The Window and Door Decoration.

The ridge decoration of Hmong people's houses is exciting and straightforward. Usually, a row of small green tiles with the same length as the roof is built on the roof of the roof, not only to compact the roof tile ridges to prevent the outer sheets from blowing away or loosening, but also as a building material reserve at any time for roof Preparing the tiles for damage. At the same time, the two ends of the ridge tile continue to be lifted with tile stacks (Figure 21), and the middle is tiled into ridge flowers. These ridge flowers made of small black tiles are assembled into triangles, coins, flowers, diamonds. They are the repository of the Hmong people's wishes for auspiciousness, well-being, prosperity, and longevity (Figure 22).
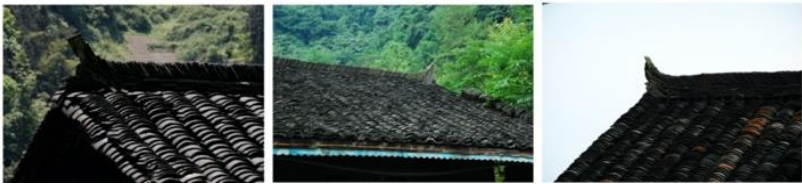

Figure 21. The Lifted with Tile Stacks. 


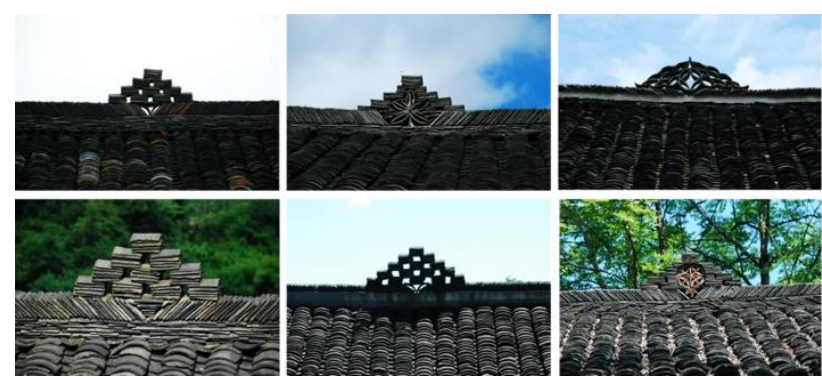

Figure 22. The Ridge Flowers.

\section{CONCLUSION}

Influenced by its unique regional, historical, cultural, and national character, the rural homes of the Hmong people in Huayuan County are subject to the natural scale from the whole courtyard to the single building, forming a distinctive feature of following the nature and skilfully choosing.

In terms of the layout of the courtyard, the Hmong's architectures are less constrained by the conventional ritual system, so the courtyard layout is flexible and changeable, and the courtyard groups are adapted to local conditions. It is showing a free space form, reflecting the Hmong people's cosmic view of harmony between heaven and man and the romantic and mysterious culture.

In the aspect of building construction, the space of dwellings keeps the orderly and precise sequence in the free courtyard pattern, and the lightness and delicacy of the modelling show a romantic and aesthetic temperament. The application of natural materials such as stone, wood, and earth strengthen the primitive, rough, and pure flavour of Hmong culture.

The Hmong vernacular dwellings in Huayuan County are the witnesses and carriers of the social life and cultural development of the Hmong people. They embody the distinctive cultural connotation of the Hmong nationality and show the unique aesthetic and romantic sentiment of the Hmong vernacular architecture to the world.

\section{ACKNOWLEDGEMENTS}

I would like to express my sincere gratitude to Professor Zhang Dayu, the corresponding author of this article, for supporting the whole process of research. Thanks to the collaborator Zhenkun Gan for his hard work on this article. I also want to give appreciates to Tian Shi, Xiangwu Wu, and Tongyi Yang of the Housing and Urban-Rural Development Bureau of Huayuan County for their full support and assistance in the investigation.

\section{REFERENCES}

Fei Xiaotong, 2001. Peasant life in China. Beijing: Commercial Press.

Gan Zhenkui, Long Lingege, 2017. Style Analyses of Youma Hmong Village at Huayuan County in Western Hunan. Journal of Human Settlements in West China, 32(05):21-26.

Guan Xueying. 2012. Study on the protection and inheritance of the architectural art of the Hmong people's residence. Master. Central University for Nationalities.
Huang Dan, 2011. Study on the Aesthetic Value of the Architectural Symbols of the Hmong Nationality. Master. Hunan University.

Hunan Provincial Department of Housing and Urban-Rural Development. 2017. Traditional Hunan Houses. Beijing: China Construction Industry Press.

Li Sihong, 2009. Researches on Characteristics of Mountian Villages and Towns in West Hunan. Master. Hunan University.

Li Xiaofeng, 2009. Dwellings in Hunan and Hubei Provinces. Beijing: China Architecture \& Building Press.

Li Zhe, Liu Su, He Shaoyao, 2010. Study on the evolution and reasons of the planar form of the Hmong people's house in western Hunan. Architectural Journal, (S1): 76-79.

$\mathrm{Li} \mathrm{Zhe}$, 2011. The research on a modern adaptation of traditional wooden houses of the minority in western Hunan. Ph.D. Hunan University.

Liang Bo, 2012. Research on the Construction Method of Traditional Folk Buildings in South Hunan. Master. Hunan University.

Liu Su, 2018. Remains of Ancient Chu Culture in Huxiang Architecture. Tianjin: Huazhong University of Science and Technology Press, (03):1-8.

Liu Su, 2008. Dwellings in Western Hunan. Beijing: China Architecture \& Building Press.

Long Boya, Wu Xinfu, 1992. Hmong History. Chengdu: Sichuan People's Publishing House.

Long Lingege, 2018. Spatial Form Analysis of Hmong Traditional Villages at Huayuan County in Western Hunan Province. Master. Beijing University of Civil Engineering and Architecture.

Peng Yigang, 1998. Architecture space combination theory. Beijing: China Construction Industry Press.

Ouyang Wen, 2002. Study on the spatial characteristics of the residential complexes in the northern mountainous area-a case study of the ancient village at the bottom of the river in Beijing. Huazhong Architecture, (03): 72-76.

Shen Hui, 2001. Research on the Development of Traditional Settlements and Traditional Dwellings in the Xiangxi Area under the Influence of Social's Progress. Master. Hunan University.

Shi Qigui, 1986. Investigation Report on Hmong People in Western Hunan. Changsha: Hunan People's Publishing House.

Wei Yili, 2010. Vernacular architecture in the west part of Hunan. Tianjin: Huazhong University of Science and Technology Press, (03):9-15.

Xiao Xiangdong, 2004. Study on the layout and space of ethnic buildings in Western Hunan. Master. Central South Forestry University.

Zhang Dayu, 2014. Spatial analysis and application of ancient villages in Beijing. Doctor. Tianjin University. 